\title{
Involvement of autophagy in ovarian cancer: a working hypothesis
}

\author{
Claudia Peracchio ${ }^{1,3}$, Oscar Alabiso ${ }^{2}$, Guido Valente ${ }^{3}$ and Ciro Isidoro ${ }^{1,4^{*}}$
}

\begin{abstract}
Autophagy is a lysosomal-driven catabolic process that contributes to preserve cell and tissue homeostases through the regular elimination of damaged, aged and redundant self-constituents. In normal cells, autophagy protects from DNA mutation and carcinogenesis by preventive elimination of pro-oxidative mitochondria and protein aggregates. Mutations in oncogenes and oncosuppressor genes dysregulate autophagy. Up-regulated autophagy may confer chemo- and radio-resistance to cancer cells, and also a pro-survival advantage in cancer cells experiencing oxygen and nutrient shortage. This fact is the rationale for using autophagy inhibitors along with anti-neoplastic therapies. Yet, aberrant hyper-induction of autophagy can lead to cell death, and this phenomenon could also be exploited for cancer therapy. The actual level of autophagy in the cancer cell is greatly affected by vascularization, inflammation, and stromal cell infiltration. In addition, small non-coding microRNAs have recently emerged as important epigenetic modulators of autophagy. The present review focuses on the potential involvement of macroautophagy, and on its genetic and epigenetic regulation, in ovarian cancer pathogenesis and progression.
\end{abstract}

Keywords: Ovary cancer, Autophagy, Inflammation, Epigenetic, MicroRNA

\section{Introduction}

Ovarian cancer ranks as the fifth leading cause of cancer-related deaths among women, and the leading cause of death from gynecological cancer [1]. The difficulty to diagnose the disease at early stage and the persistence of dormant, drug-resistant cancer cells that cause relapse, are the primary reasons for the high mortality rate in ovarian cancer patients [2]. First-line therapy for advanced stage disease includes maximal surgical debulking followed by platinum/taxane chemotherapy, which attains initial response rates of over $80 \%$ [3]. However, most patients will eventually relapse with chemoresistant tumors. The propensity to trigger a program of epithelial-to-mesenchymal transition, the over-expression of drug efflux transporters and the persistence of dormant cancer stem cells are the principal factors that determine the recurrence and progression of ovarian cancer. The poor prognosis in ovarian cancer patients poses the urge to identify novel

\footnotetext{
* Correspondence: isidoro@med.unipmn.it

'Laboratory of Molecular Pathology and Nanobioimaging, Department of

Health Sciences, Novara, Italy

${ }^{4}$ Department of Health Sciences, Università del Piemonte Orientale "A.

Avogadro", Via Solaroli 17, 28100, Novara, Italy

Full list of author information is available at the end of the article
}

and more reliable (in terms of sensitivity and specificity) biomarkers for the detection of the disease in its (very) early stage, for monitoring the response to treatments, and possibly for targeted molecular therapy [4]. Recently, autophagy dysregulation in cancer cells has been blamed as a possible cause of dormancy and of resistance to radio- and chemotherapeutic treatments, and proteins involved in the regulation of this process are being considered as targets for anticancer molecular therapy. In this review, we discuss the involvement of (macro)autophagy in the pathogenesis of ovarian cancer, and on the genetic and epigenetic factors that potentially regulate this process. We also discuss the clinical implications of the role of autophagy in ovarian cancer for diagnosis, prognosis and therapy purposes.

\section{Morphology of autophagy at a glance}

Autophagy literally means (from Greek) 'self-eating', and refers to a cellular process committed to the lysosomal degradation of self constituents [5]. So far, three different types of autophagy (macroautophagy, microautophagy and chaperon-mediated autophagy) have been described, which essentially differ for the mechanism through which the target substrates gain access to the lysosomal 
lumen. In the case of macroautophagy (now on simply referred to as autophagy), macromolecular aggregates, portion of cytoplasm, membranes and entire organelles are sequestered within newly formed vesicles (named autophagosomes) that subsequently fuse with lysosomes [6]. In the case of microautophagy, cytoplasmic material and organelles are directly internalized by the lysosome through invagination of the lysosomal membrane [7]. In the case of chaperon-mediated autophagy, cytoplasmic proteins bearing the consensus sequence KFERQ at the C-terminus are assisted to enter the lysosome by the chaperon Hsc70, which interacts with the lysosomal membrane protein Lamp2A [8]. Schematically, three main operational steps characterize the autophagy process (Figure 1): (1) sequestration of the material into a newly formed vesicle; (2) fusion of this vesicle with lysosomal organelles; and (3) degradation of the material and recycling of the substrates. These steps have been widely characterized at morphological level [9], and new guidelines for their assessment have been recently released [10]. The hallmark of autophagosome formation is represented by the insertion within the inner and outer layers of the vesicle of LC3 II (isoform II of Light Chain), which is generated from the precursor Microtubule Associated Protein (MAP-LC3) by partial proteolysis and subsequent lipidation at its C-terminus [11]. The fusion of the autophagosome with late endosomes and lysosomes can be assessed by co-labeling LC3 and Lamp1 (the latter is a Lysosomal Associated Membrane Protein). Another means to look at the autophagy flux is to follow the degradation of p62/SQSTM1, a protein that links ubiquitinated protein aggregates to LC3 [12]. Once the autophagolysosome has formed, acid hydrolases (particularly, the cathepsins) degrade the sequestered material, and the substrates are recycled for biosynthetic processes $[13,14]$.

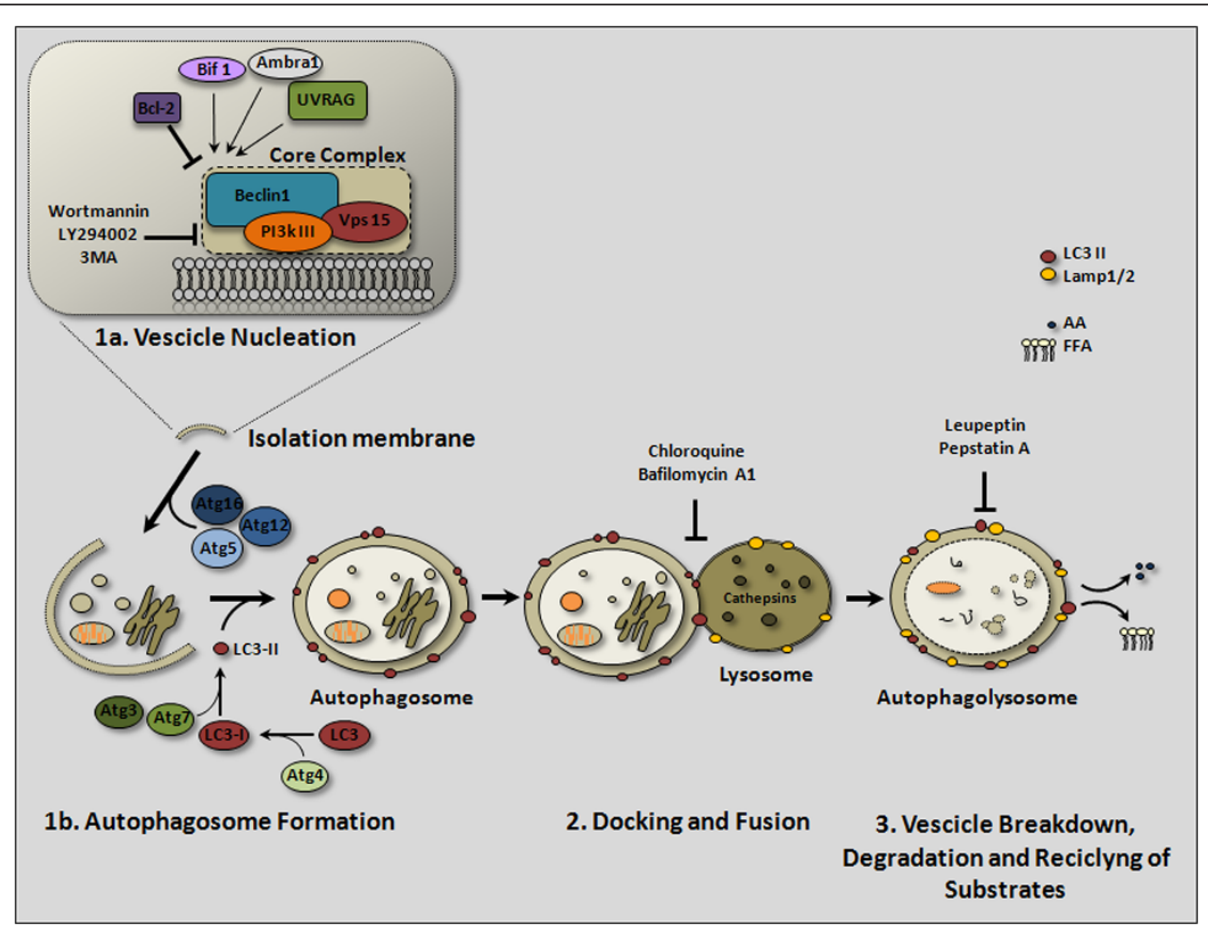

Figure 1 Flow-chart showing the three principal steps of the (macro)autophagy process. The first step starts with the vesicle nucleation from a pre-existing isolation membrane and terminates with the formation of an autophagosome that entraps cellular materials. The core complex of the autophagy interactome, and some other beclin 1 interactors, are shown in the inset. The kinase activity of PI3k class III can be inhibited by Wortmannin, LY294002 or 3-methyadenine (3MA). The interaction of bcl-2 with beclin 1 precludes the formation of the beclin 1-PI3k III complex. JNK-mediated phosphorylation of bcl-2 or DAPk-mediated phosphorylation of beclin 1 disrupts the bcl-2/beclin 1 interaction, and thus favors the formation of the autophagy interactome. During vesicle nucleation and expansion, a lipidated LC3-II isoform is included in both the internal and external membrane of the autophagosome. Atg4 plays a crucial role in the generation of LC3 II from LC3 I. Other Atg proteins (namely, atg3, atg5, atg7 and atg12) participate in the process of lipidation (i.e., conjugation with phosphatydil choline) and membrane insertion of LC3 II. The second step consists in the docking and fusion of the autophagosome with several endosomes and lysosomes to form the autophagolysosome. This step can be inhibited by drugs that increase the lysosome pH (e.g. Chloroquine, Bafilomycin A1). The third step consists in the degradation of the autophagic vesicle and of its cargo by acid hydrolases, and subsequent release of substrates (essentially AA, aminoacids; FFA, free fatty acids) for reutilization. The lysosomal degradation step can be inhibited by protease inhibitors (e.g., Leupeptin, Pestatin A) or by raising the internal $\mathrm{pH}$. 


\section{Biochemical regulatory aspects of autophagy}

The biochemical regulation of autophagy has been the subject of excellent recent reviews, to which the readers may refer for a detailed description [15,16]. A variety of protein- and lipid-kinases, protein- and lipidphosphatases, and mono and trimeric GTPases control the induction and progression of autophagy [15-19]. A simplified network of the main regulatory pathways is illustrated in Figure 2. Classically, the starting signal for the formation of the autophagosome is the synthesis of phosphatydil-inositol-3-phosphate (PI3P) molecules by the PI3k class III kinase (also known as Vps34), which becomes active upon interaction with Beclin 1 (homologue of Vps30/Atg6) [20, see also Figure 1]. By contrast, the production of phosphatydil-inositol3,4,5-phosphate (PIP3) by class I PI3k keeps basal autophagy at low level through the activation of the Akt pathway [21]. The lipid phosphatase activity of the oncosuppressor PTEN, which removes the phosphate in position 3 from PIP3, counteracts the activation of Akt and therefore allows autophagy [22]. A crucial player in the regulation of autophagy is mTOR (mammalian Target of Rapamycin), whose kinase activity inhibits Atg1/ULK1 and the formation of the autophagy interactome [18]. While the Akt pathway negatively regulates autophagy through the activation of

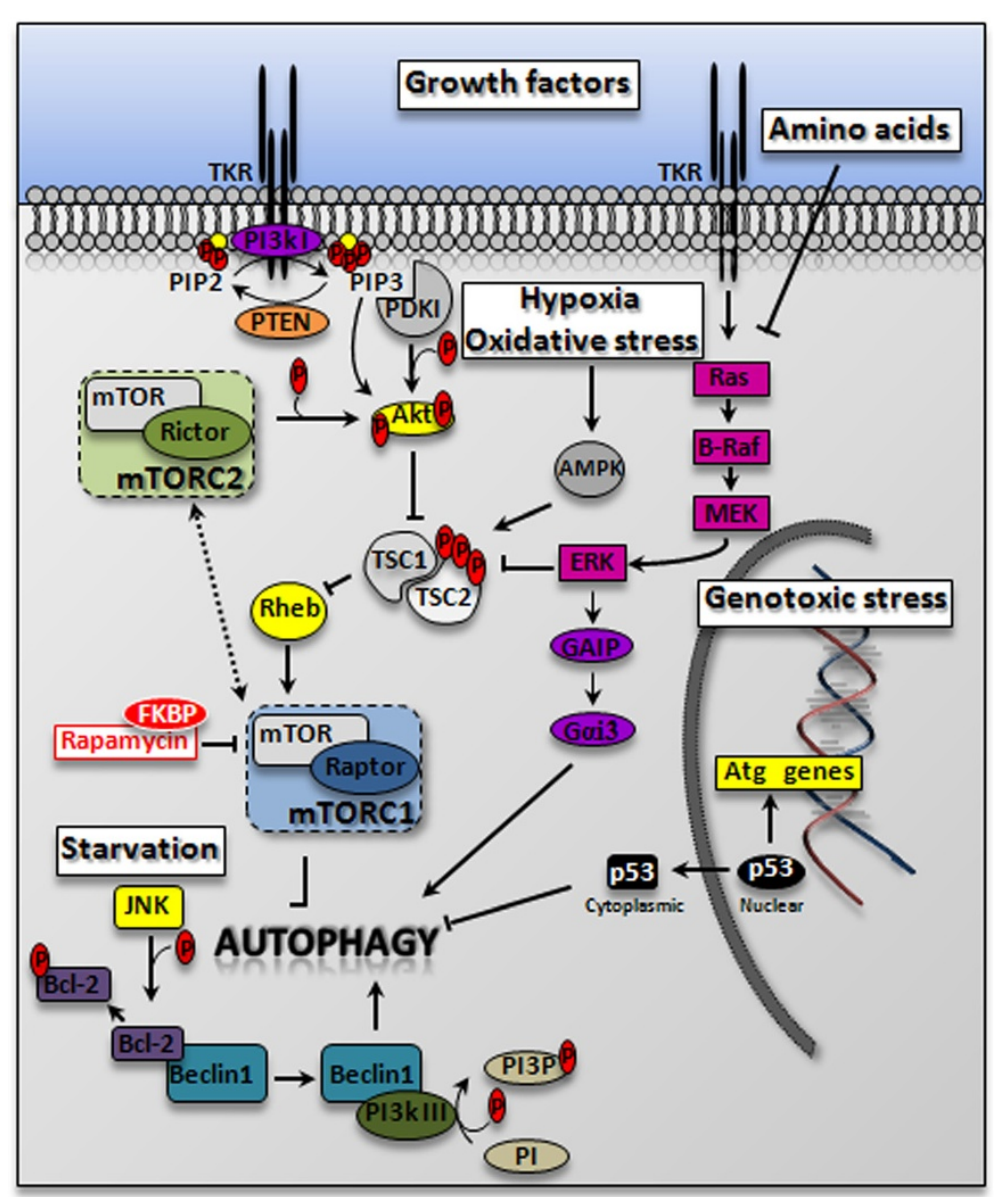

Figure 2 Signaling pathways impinging on autophagy. The scheme illustrates the network of the principal kinases involved in the regulation of autophagy. Essentially, growth factors activate the mTORC1 complex (trough the inhibition of the TSC1/TSC2 complex), and this results in the inhibition of the ULK1(ATG1) complex and prevents the induction of autophagy. The abundance of aminoacids also results in down-regulation of this pathway through the inhibition of the Ras-Mek-Erk pathway, and by direct activation of mTOR through the RagA/B GTPases complex (not shown in the scheme). The lipid-kinase activity of PTEN prevents the activation of the Akt-mTOR pathway, and therefore removes the tonic inhibition of autophagy exerted by this pathway. This tonic inhibition can be also removed artificially by pharmacologic inhibition of mTOR with Rapamycin. Hypoxia and mitochondrial oxidative stress inhibit mTOR through the action of AMPk on the TSC1/TSC2 complex. Starvation (amino acid deprivation) activates the JNK pathway, which ends with the phosphorylation of bcl-2, thus allowing the formation of the autophagy interactome. Once activated, Vps34 produces PI3P, which acts as a platform for other autophagy proteins involved in autophagosomal membrane nucleation and elongation. A genotoxic stress activates p53 and other transcription factors (e.g., TFEB) that promote the synthesis of autophagy proteins (e.g., DRAM, UVRAG, cathepsin D). However, high levels of cytoplasmic p53 (localized in the endoplasmic reticulum) result in the inhibition of autophagosome formation. 
mTOR, the AMPk pathway, which senses the lack of ATP, inhibits mTOR and directly activates Atg1 (homologue of ULK1), thus promoting autophagy in response to stressors [23]. It follows that activation of autophagy may occur in the presence of phosphorylated Akt, provided that mTOR is inactivated [24]. It is to be mentioned that autophagy may also be induced bypassing the mTOR control, for instance by increasing the level of Inosytol-tri-phosphate (IP3) [25]. Remarkably, at variance of the canonical pathway described above, mammalian cells can activate alternative pathways for autophagic degradation in which certain autophagy proteins (e.g., Beclin-1, Vps34, Atg5, Atg7, ULK1) are dispensable (reviewed in [26]).

Simplifying, amino acids and growth factors keep mTOR active and prevent the hyper-induction of autophagy, whereas nutrient shortage and energy depletion increase the level of basal autophagy (Figure 2).

\section{Functional significance of autophagy in normal and in cancer cells}

Autophagy accomplishes two fundamental physiological activities: (1) it constitutively degrades and recycles redundant and aged molecules and organelles, and (2) it destroys abnormal and potentially harmful molecular and cellular components [15]. To understand the role of autophagy in cell physiology and pathology it is fundamental to distinguish basal and induced autophagy. Basal (constitutive) autophagy prevents unwanted and unnecessary increases in cell mass by eliminating exuberant and exceeding cellular structures, thus greatly contributing to cell homeostasis. In normal cells, constitutive autophagy is subjected to modulation depending on the metabolic state of the cell: while in growing cells active mTOR exerts a tonic inhibitory control that keeps constitutive autophagy at low basal level, in normal quiescent cells constitutive autophagy is up-regulated to equilibrate synthesis in order to allow the macromolecular turnover without net increases in cell mass. On demand, autophagy can be transitorily hyper-induced, for instance to meet the need to recover from nutrient or energy depletion, or to contrast the accumulation of damaged molecules and organelles. In cancer cells autophagy is clearly dysregulated. The strict connection between autophagy and carcinogenesis is supported by the fact that numerous oncogene and oncosuppressor proteins regulate both processes [27]. Autophagy plays a complex and apparently contradictory role in the various phases of cancer development and progression. In fact, by avoiding the accumulation of damaged molecules and organelles that may increase the probability of oxidative stress-mediated DNA mutation, basal autophagy prevents cell transformation [28]. Consistently, loss-offunction of genes that positively regulate autophagy, such as Beclin-1 [29,30] or PTEN [31], predisposes to spontaneous cancers. On the other hand, when a chemotherapeutics induces oxidative stress and DNA damage or when defective vascularization determines hypoxia and starvation, the up-regulation of autophagy enables cancer cells to overcome the metabolic stress $[32,33]$. In such circumstances, up-regulation of autophagy associated with down-regulation of apoptosis contributes to chemoresistance. Further, a long-lasting up-regulation of basal autophagy may favor a senescent/ dormancy state in cancer cells [34], and likely in cancer stem cells as well, that resist to radio- and chemotherapy, and could be re-activated and give rise to recurrent cancer.

\section{Epigenetic regulation of autophagy: the role of histone deacetylases, of microRNAs, and of the tumor microenvironment}

Besides the fact that autophagy can be dys-regulated as a consequence of mutations in autophagy-related genes, including oncogenes and oncosuppressor genes, the possibility that the actual level of autophagy in cancer cells is dynamically influenced by epigenetic factors should be taken into account. The principal intrinsic epigenetic regulation occurs at transcriptional level, through modulation of DNA methylation and histone acetylation, and at post-transcriptional level through microRNA (miRNA)-mediated degradation of mRNA. For instance, the expression of ARH1 gene, an oncosuppressor that regulates autophagy (see below), is repressed in many cancers, including ovarian cancers, due to hypermethylation of its promoter [35]. Moreover, certain miRNAs, a class of small non-coding RNAs, have recently emerged as important epigenetic modulators of autophagy in cancer cells (reviewed in [36]). The mRNA of several autophagy-related genes contains, in fact, the target sequence for miRNAs belonging to different families, with either oncosuppressive or oncogenic activities. For instance, Beclin-1 mRNA can be targeted by oncosuppressive members of the miR30 family [37] and by oncogenic miR-376b [38]; the mRNA of ATG4C is downregulated by oncogenic miR-376b [38] and that of ATG4D by oncosuppressive miR-101 [39]; the mRNA of p62/SQSTM is targeted by miR-17/20/93 and miR106 [40], while the expression of MAP-LC3 can be affected by miR196 [41], and the translation of ATG7 mRNA is suppressed by miR375 [42]. Finally, autophagy can be modulated through modulation of hystone acetylation/ deacetylation by the hystone deacetylases HDAC4 and HDAC5, which are targeted by miR-9-3p [43]. To be noted, HDAC6 promotes the autophagic flux by regulating the acetylation status of cytoskeleton proteins [44].

Additional mechanisms of epigenetic regulation involve extracellular signals. In fact, microenvironmental 
factors (hypoxia, pH, oxidative stress, nutrient availability, cytokines, hormones and growth factors) and the physical-metabolic interaction with surrounding cells (inflammatory cells, fibroblasts) in the matrix greatly influence the autophagy compliance of the tumor cell [4547]. The scarce vascularization in the most inner portion of the tumor determines a situation of hypoxia and starvation, which cause the activation of autophagy driven by the Hypoxia Inducible Factor HIF-1 $\alpha$ [48] and by AMPk [49], thus conferring a survival advantage to cancer cells. On the other hand, in the highly vascularized area of the tumor, the presence of nutrients limits autophagy and favors the growth of cancer cells. In addition, cancer associated fibroblasts, inflammatory cells (especially type- 2 macrophages) and cytokines (e.g., IL-1 $\beta$, TNF- $\alpha$ and IL-6) have been shown to affect the regulation of autophagy in cancer cells through induction of a metabolic stress [47,50-52].

\section{Involvement of autophagy in ovarian cancer}

According to genetic and pathologic features, epithelial ovarian cancer are classified in Type I tumors, characterized by a variety of somatic mutations or amplification/ deletion of oncogenes or oncosuppressors including KRAS, B-RAF and PTEN, and Type II tumors, which are chromosomally unstable, and present with mutated or deleted TP53 (in more than $80 \%$ of the cases) and BRCA inactivation (in up to $30 \%$ of the cases) [53,54]. Type- 1 ovarian cancers comprise clinically indolent, low grade serous and endometrioid carcinomas, clear cells and mucinous carcinomas; type- 2 ovarian cancers comprise aggressive, high-grade serous and endometrioid carcinomas, malignant mixed mesodermal carcinomas, and undifferentiated carcinomas [53,54]. Besides the genetic alterations, it is now becoming clear that also epigenetic mechanisms play a role in the development of ovarian cancer [55]. Yet, the mechanisms involved in epithelial ovarian cancer pathogenesis and progression are still largely obscure. Autophagy dysregulation might play an important role in the pathogenesis, as well as in resistance to radio- and chemotherapeutic treatments and in dormancy in ovarian cancer. Indeed, a number of oncogenes and oncosuppressor genes have been found deregulated in ovarian cancers because of genetic or epigenetic alterations [56,57], and many of these potentially impact on autophagy regulation. Furthermore, a plethora of proteins whose expression has been found altered in ovarian cancers may directly or indirectly affect autophagy at different level. Schematically, the genes found altered in ovarian cancer that have an impact on autophagy belong to: (1) the oncosuppressors PTEN, ARHI and $\mathrm{p} 53$, that regulate autophagy, apoptosis and dormancy; (2) the components of the autophagy machinery LC3, beclin-1 and DRAM; (3) the growth factor and nutrient sensor signaling pathways, which include the class I PI3-k/Akt/mTOR and the Ras/Raf/ERK pathways.

As compared to benign hyperplastic tissues and borderline ovarian tumors, poorly differentiated and highly malignant ovarian cancer cells were shown to express very low level of the autophagy protein LC3 [58], indicating that LC3-labeled autophagosomes do not accumulate in highly aggressive ovarian cancers. Whether this phenomenon underlies the inability to form autophagosomes or rather reflects their efficient removal by the lysosomal system remains to be elucidated. Mutation and deletion of the oncosuppressor P53 gene has been reported in $60-80 \%$ of both sporadic and familial ovarian cancers [56]. DNA-binding deficient p53 mutants are unable to sequester bcl- 2 or bcl-XL, and display a dominant negative activity. $\mathrm{Bcl}-2$ can inhibit the formation of the autophagy interactome by interacting with beclin 1 [20], and therefore the over-expression of such mutated p53 in ovarian cancer cells may indirectly impact on autophagy. In addition, p53 mutants that permanently localizes in the cytoplasm have been shown to inhibit autophagy [59]. ARH1 (Aplasia Ras Homolog member I; also known as DIRAS3), which encodes a ras-homolog $26 \mathrm{kDa}$ GTPase, is a tumor suppressor gene imprinted down-regulated in ovarian cancers [60]. Re-expression of ARH1 suppresses proliferation, motility and angiogenesis $[61,62]$ and promotes cell death [63] in ovarian cancer cells. Of note, ARH1 protein has recently been shown to up-regulate autophagy (through inhibition of the mTOR pathway) and to induce autophagydependent dormancy in ovarian cancer cells [34]. The latter finding implies that re-activation of ARHI can enable ovarian cancer cells to overcome metabolic stress and to survive in a dormant state in appropriate tumor microenvironment. As stated above, active mTOR exerts a tonic inhibition on basal autophagy. It is intriguing, in this respect, the finding that a hyper-active status of mTOR is associated with a poor prognosis in ovarian carcinoma patients [64]. Sustained up-regulation of the class I PI3k-Akt-mTOR axis in ovarian cancers may arise from activating mutation or duplication of genes coding for the Tyrosin Kinase Receptors EGFR and PDGFR, for PI3kCA or Akt $[65,66]$, as well as by inactivating mutations of PTEN [67] or hyper-expression of the PTEN-regulator protein DJ-1 [68]. BECLIN 1 has been the first oncosuppressor gene that proved the link between autophagy and cancerogenesis [69]. Of note, monoallelic deletion of BECLIN 1 is found in more than $50 \%$ of sporadic ovarian cancers [69]. Accordingly, the expression of beclin 1 was found down-regulated in ovarian cancers, compared to benign lesions [58]. Consistent with a role of autophagy-active beclin 1 in ovarian cancer progression, we found that hyper-expression of both beclin 1 and LC3 in ovarian cancer cells was 
associated with a good chemotherapeutic response in patients (Peracchio et al., unpublished data; Figure 3). Another autophagy-regulator gene associated with ovarian cancer progression is DRAM (Damage-Regulated Autophagy Regulator), a p53-trancribed gene that codes for a lysosomal-associated protein involved in apoptosis and autophagy [70]. Recently, it has been reported that the homologous DRAM2, which also induces autophagy [71], is expressed at very low level in aggressive ovarian tumors [72]. Transgenic overexpression of PEA-15, the $15 \mathrm{kDa}$ Phospho-Enriched protein in astrocytes, has recently been shown to induce autophagy and non-apoptotic cell death in ovarian cancer cells through the activation of the ERK pathway [73]. It is intriguing to observe that women bearing an ovarian cancer with high level of expression of PEA-15 have an overall survival longer than those bearing a low-PEA15-expressing cancer [73]. In aggregate, the data so far available consistently indicate that an intrinsic defect in the activation of autophagy leads to a more aggressive progression of ovarian cancer.

\section{Epigenetic factors that impinge on autophagy in ovarian cancer}

As mentioned above, autophagy in cancer cells is subjected to fluctuations depending on extracellular stimuli, the availability of oxygen and nutrients, and also on the actual expression of certain microRNAs. Ovarian cancer cells release chemotactic cytokines and growth factors that recruit fibroblasts, endothelial cells and macrophages, which in turn contribute with their own secretions to form a dynamic tumor microenvironment [74,75]. A number of inflammatory-related proteins abnormally present in the tumor context or in the ascitic fluid, and associated with ovarian cancer progression, could directly or indirectly affect autophagy. For instance, TNF $\alpha$, a cytokine involved in ovarian cancer growth and metastasis [74], is a potent activator of NF$\mathrm{kB}$, which in turn activates the anti-apoptotic and antiautophagic Akt/mTOR pathway. IL-6 is a proinflammatory cytokine highly expressed in the tumor context of type- 2 ovarian cancers and in ascitic fluid, and its level correlates with poor prognosis in ovarian cancer patients [76,77]. IL-6 promotes VEGF-mediated
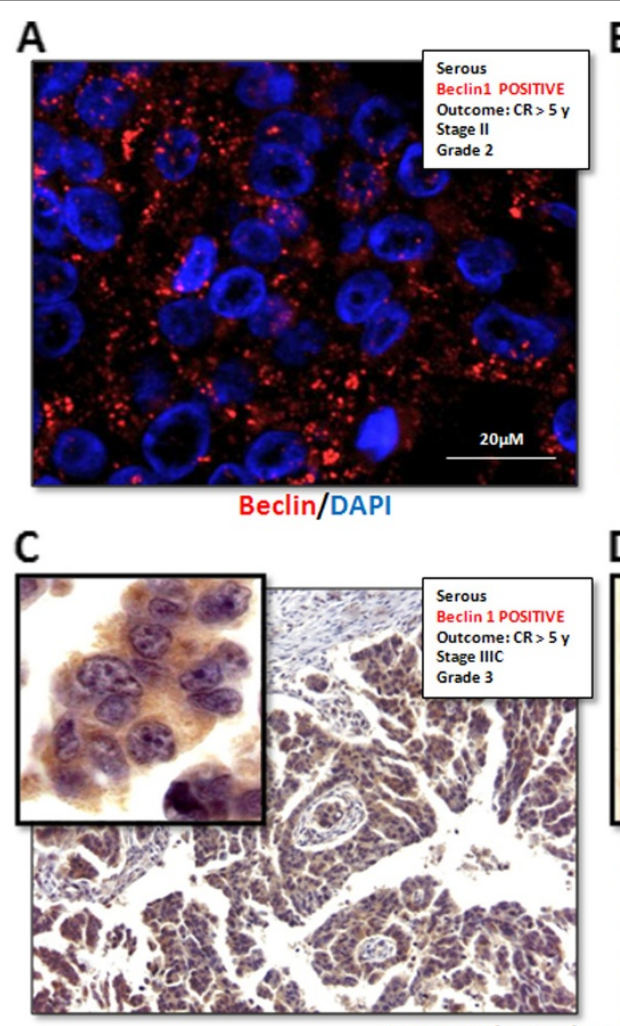

Immunohistochemistry of Beclin1
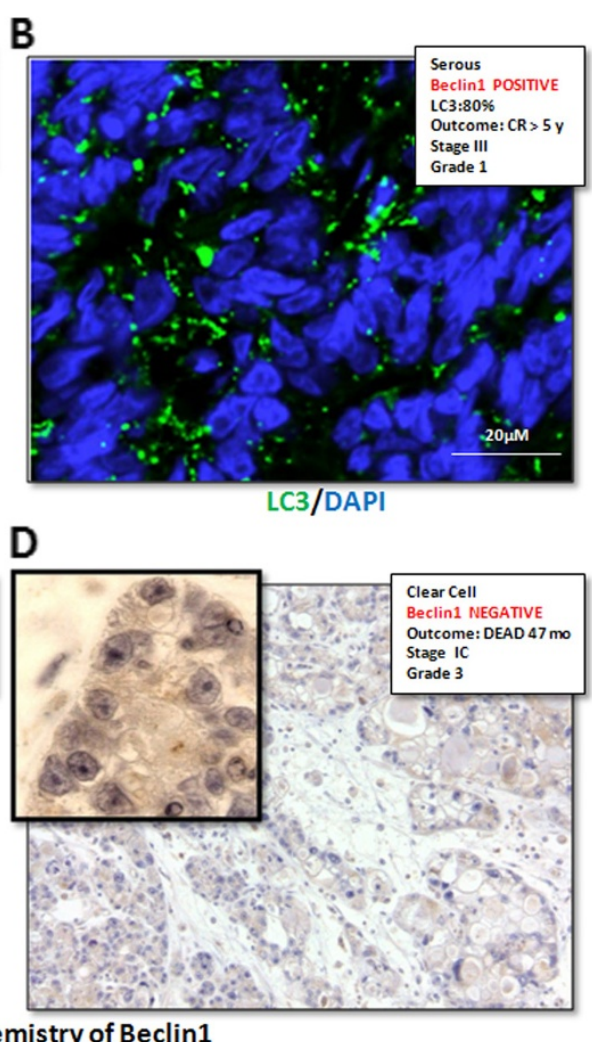

LC3/DAPI

D

Figure 3 Immunodetection of autopahgy proteins in ovarian cancer tissue sections. Immunofluorescence positivity for beclin 1 (panel A) and LC3 (panel B) appears as discrete puncta (indicative of protein clusterization) in the cytoplasm of cancer cells. A high level of expression of beclin 1 and of LC3 (positivity in $>40 \%$ of cancer cells) was found to correlate with good prognosis (CR, complete remission at 5 years of follow up). Immunohistochemistry of beclin 1 in a positive (panel C) and in a negative (panel D) case is also shown (magnification 420x). The presence or absence of beclin 1 aggregates can be appreciated in the high-magnification (1050x) area shown in the insets. 
vasculogenesis and angiogenesis, especially in aggressive type-2 ovarian cancers [77]. Lysophosphatidic acid (LPA), abundantly released by ovarian cancer cells, is known to contribute to ovarian cancer aggressiveness by stimulating the synthesis of IL-6 and of VEGF $[78,79]$, among others. Of note, while IL-6 acts as an inducer [80], LPA was shown to inhibit autophagy induced by serum deprivation in prostate cancer cells [81]. These data outline how the microenvironment and the cytokine network dynamically affect autophagy in ovarian cancer cells. In the epigenetic control of autophagy, a further level of complexity is brought by the dynamic changes in the expression of miRNAs. The profile of miRNAs pattern in ovarian cancer cells varies during development and progression phases [82-84]. Although a thorough analysis of miRNA-mediated regulation of autophagy in ovarian cancer cells has not yet been performed, we can speculate in this sense based on the information available. For instance, miR-30a, which negatively regulates the expression of Beclin 1 [37], was found downregulated in samples from relapsing patients diagnosed with stage I ovarian cancer [85]; and miR-101, which represses the expression of the autophagy protein Atg4 [39], was found down-regulated in ovarian cancer compared to normal tissue [86]. MiR-101 targets also the mRNA of STMN1 and RAB5A [39]. Of note, stathmin over-expression showed a significant association with poor prognosis in ovarian cancer patients [87], and Rab5A was shown to promote cell proliferation in ovarian cancer [88]. Finally, miR-214 and mir-21, respectively associated with the chemoresistant phenotype [89] and the metastatic potential of ovarian cancer cells [90], have been shown to target PTEN, the oncosuppressor known to positively regulate autophagy and to be mutated or deleted in a vast majority of ovarian carcinomas. With regard to the transcriptional level of epigenetic regulation of autophagy in ovarian cancer, the oncosuppressors PTEN, ARH1 and DAPk (Death-associated protein kinase) merit to be mentioned. The hyper-methylation of PTEN promoter is not a frequent finding in ovarian cancer specimen [91]. By contrast, ARH1 and DAPk are among the most frequently down-regulated tumor suppressors in ovarian cancers due to promoter methylation $[35,91]$. Under stressful conditions, DAPk phosphorylates beclin-1, promoting its dissociation from bcl-2, and thus inducing autophagy [92].

\section{Clinical implications and future perspectives}

Targeting of the autophagy pathway is being under evaluation as a new anti-cancer therapeutic option [93-95]. Data in the literature show that both autophagy enhancer and autophagy inhibitor drugs may elicit beneficial effects by inducing cancer cell death. This apparent contradiction could be explained considering the complex role that autophagy plays in cancer cells in the different phases of carcinogenesis, and in dependence of the tumor context. In fact, while at the precancerous stage an autophagy defect would facilitate genomic instability and tumor development, in growing tumors the up-regulation of autophagy compensates for the limited nutrient supply and helps to face genotoxic and metabolic stresses [96,97]. The latter phenomenon constitutes the rationale for using inhibitors of the late step of the autophagy process (e.g., chloroquine) together with traditional anti-neoplastics [93-95]. In certain circumstances, the excessive and sustained up-regulation of autophagy (for instance under prolonged starvation, oxidative stress or metabolic impairment) has been associated with cell death $[98,99]$. This observation constitutes the rationale for using drugs that induce autophagy, such as rapamycin and its analogs [93-95]. The switch from a pro-survival to a pro-death outcome of autophagy activation could also be exploited in cancer therapy. Relevant to the present study, a phase II clinical trial for the treatment of endometrioid ovarian cancer with an mTOR inhibitor is currently ongoing [100]. At present, 22 clinical trials (of which 2 are terminated) are using rapamycin or its analogs in combination with other drugs for the treatment of ovarian cancer (http://www.clinicaltrials.gov). Another drug that has been proposed as a molecular therapeutics for the treatment of ovarian cancers is the anticonvulsant Valproic acid (VPA), which acts as a histone-deacetylase inhibitor [4]. At present, 2 ongoing clinical trials are using VPA alone or in combination with Carboplatin for the treatment of ovarian cancer (http://www.clinicaltrials.gov). VPA and tubacin (another histone deacetylase) kill ovarian cancer cells at doses that specifically inhibit HDAC6 [101], which is known to favor the fusion of autophagosomes with lysosomes through the deacetylation of tubulin and actin [44]. Thus, targeting autophagy might be a strategy to combat ovarian cancers that have developed chemoresistance to traditional antiblastic therapies. However, it must be kept in mind that the efficacy of autophagy-based therapies strictly depends on the actual level of ongoing autophagy in the tumor cells, which is dictated by genetic mutations, but also influenced by the epigenetic regulation of relevant genes, as mediated by the tumor microenvironment (namely the vascularization and the extent of the infiltration by fibroblasts and immuno-inflammatory cells) and by certain miRNAs. The unraveling of clinical implications of genetic and epigenetic factors involved in autophagy dysregulation in ovary cancer might hopefully open the way to new diagnostic and therapeutic approaches for this malignant disease.

\section{Competing interests}

The authors declare that they have no competing interests. 


\section{Authors' contributions}

CP performed the immunofluorescence staining, made the bibliography search and drew the schemes; GV performed the immunohistochemistry; GV and OA participated in the critical assessment of the manuscript. $\mathrm{Cl}$ organized the structure of the review and wrote the manuscript. All authors read and approved the final manuscript.

\section{Acknowledgements}

The authors fully acknowledge the funding support from Comoli, Ferrari \& SpA (Novara, Italy) and from Associazione per la Ricerca Medica IppocrateRhazi (Novara, Italy). Authors are thankful to Dr S. Canevari (National Institute of Cancer, Milan) for helpful discussion.

\section{Author details}

${ }^{1}$ Laboratory of Molecular Pathology and Nanobioimaging, Department of Health Sciences, Novara, Italy. ${ }^{2}$ Unit of Oncology, Department of Translational Medicine, Azienda Ospedaliero-Universitaria "Maggiore della Carità", Novara, Italy. ${ }^{3}$ Laboratory of Pathology, Department of Translational Medicine, Università del Piemonte Orientale "A. Avogadro", Novara, Italy. ${ }^{4}$ Department of Health Sciences, Università del Piemonte Orientale "A. Avogadro", Via Solaroli 17, 28100, Novara, Italy.

Received: 31 July 2012 Accepted: 11 September 2012 Published: 13 September 2012

\section{References}

1. Jemal A, Bray F, Center MM, Ferlay J, Ward E, Forman D: Global cancer statistics. CA Cancer J Clin 2011, 61:69-90.

2. Clarke-Pearson DL: Clinical practice. Screening for ovarian cancer. N Engl J Med 2009, 361:170-177.

3. Guarneri $V$, Piacentini F, Barbieri E, Conte PF: Achievements and unmet needs in the management of advanced ovarian cancer. Gynecol Oncol 2010, 117:152-158.

4. Hiss D: Optimizing molecular-targeted therapies in ovarian cancer: the renewed surge of interest in ovarian cancer biomarkers and cell signaling pathways. J Oncol 2012, 2012:737981.

5. Yang Z, Klionsky DJ: Eaten alive: a history of macroautophagy. Nat Cell Biol 2010, 12:814-822.

6. Itakura E, Mizushima N: Characterization of autophagosome formation site by a hierarchical analysis of mammalian Atg proteins. Autophagy 2010, 6:764-776.

7. Mijaljica D, Prescott M, Devenish RJ: Microautophagy in mammalian cells: revisiting a 40-year-old conundrum. Autophagy 2011, 7:673-682.

8. Kaushik S, Bandyopadhyay U, Sridhar S, Kiffin R, Martinez-Vicente M, Kon M, Orenstein SJ, Wong E, Cuervo AM: Chaperone-mediated autophagy at a glance. J Cell Sci 2011, 124:495-499.

9. Eskelinen EL, Reggiori F, Baba M, Kovács AL, Seglen PO: Seeing is believing: the impact of electron microscopy on autophagy research. Autophagy 2011, 7:935-956

10. Klionsky DJ, 1269 others: Guidelines for the use and interpretation of assays for monitoring autophagy. Autophagy 2012, 8:445-544.

11. Fujita N, Itoh T, Omori H, Fukuda M, Noda T, Yoshimori T: The Atg16L complex specifies the site of LC3 lipidation for membrane biogenesis in autophagy. Mol Biol Cell 2008, 19:2092-2100.

12. Pankiv $S$, Clausen $T H$, Lamark $T$, Brech $A$, Bruun JA, Outzen $H$, Øvervatn $A$, Bjørkøy G, Johansen T: p62/SQSTM1 binds directly to Atg8/LC3 to facilitate degradation of ubiquitinated protein aggregates by autophagy. J Biol Chem 2007, 282:24131-24145

13. Eskelinen EL, Saftig P: Autophagy: a lysosomal degradation pathway with a central role in health and disease. Biochim Biophys Acta 2009, 1793:664-673

14. Skop V, Cahová M, Papáčková Z, Páleníčková E, Daňková H, Baranowski M, Zabielski P, Zdychová J, Zídková J, Kazdová L: Autophagy-lysosomal pathway is involved in lipid degradation in rat liver. Physiol Res 2012, 61:287-297

15. Ravikumar B, Sarkar S, Davies JE, Futter M, Garcia-Arencibia M, GreenThompson ZW, Jimenez-Sanchez M, Korolchuk VI, Lichtenberg M, Luo S, Massey DC, Menzies FM, Moreau K, Narayanan U, Renna M, Siddiqi FH, Underwood BR, Winslow AR, Rubinsztein DC: Regulation of mammalian autophagy in physiology and pathophysiology. Physiol Rev 2010, 90:1383-1435
16. Mehrpour M, Esclatine A, Beau I, Codogno P: Overview of macroautophagy regulation in mammalian cells. Cell Res 2010, 20:748-762

17. Burman C, Ktistakis NT: Regulation of autophagy by phosphatidylinositol 3-phosphate. FEBS Lett 2010, 584:1302-1312

18. Jung $\mathrm{CH}$, Ro SH, Cao J, Otto NM, Kim DH: mTOR regulation of autophagy. FEBS Lett 2010, 584:1287-1295.

19. Ogier-Denis E, Couvineau A, Maoret JJ, Houri JJ, Bauvy C, De Stefanis D, Isidoro C, Laburthe M, Codogno P: A heterotrimeric Gi3-protein controls autophagic sequestration in the human colon cancer cell line HT-29. J Biol Chem 1995, 270:13-16.

20. He C, Levine B: The Beclin 1 interactome. Curr Opin Cell Biol 2010, 22:140-149.

21. Petiot A, Ogier-Denis E, Blommaart EF, Meijer AJ, Codogno P: Distinct classes of phosphatidylinositol 3'-kinases are involved in signaling pathways that control macroautophagy in HT-29 cells. J Biol Chem 2000, 275:992-998.

22. Arico S, Petiot A, Bauvy C, Dubbelhuis PF, Meijer AJ, Codogno P, OgierDenis $\mathrm{E}$ : The tumor suppressor PTEN positively regulates macroautophagy by inhibiting the phosphatidylinositol 3-kinase/protein kinase B pathway. J Biol Chem 2001, 276:35243-35246.

23. Alexander A, Cai SL, Kim J, Nanez A, Sahin M, MacLean KH, Inoki K, Guan KL, Shen J, Person MD, Kusewitt D, Mills GB, Kastan MB, Walker CL: ATM signals to TSC2 in the cytoplasm to regulate mTORC1 in response to ROS. ProC Natl Acad Sci USA 2010, 107:4153-4158.

24. Castino R, Fiorentino I, Cagnin M, Giovia A, Isidoro C: Chelation of lisosomal iron protects dopaminergic SH-SY5Y neuroblastoma cells from hydrogen peroxide toxicity by precluding autophagy and Akt dephosphorylation. Toxicol Sci 2011, 123:523-541.

25. Fornai F, Longone P, Ferrucci M, Lenzi P, Isidoro C, Ruggieri S, Paparelli A: Autophagy and amyotrophic lateral sclerosis: The multiple roles of lithium. Autophagy 2008, 4:527-530.

26. Codogno P, Mehrpour M, Proikas-Cezanne T: Canonical and non-canonical autophagy: variations on a common theme of self-eating? Nat Rev Mol Cell Biol 2011, 13:7-12.

27. Maiuri MC, Tasdemir E, Criollo A, Morselli E, Vicencio JM, Carnuccio R, Kroemer G: Control of autophagy by oncogenes and tumor suppressor genes. Cell Death Differ 2009, 16:87-93.

28. Mathew R, Kongara S, Beaudoin B, Karp CM, Bray K, Degenhardt K, Chen G, Jin S, White E: Autophagy suppresses tumor progression by limiting chromosomal instability. Genes Dev 2007, 21:1367-1381.

29. Qu X, Yu J, Bhagat G, Furuya N, Hibshoosh H, Troxel A, Rosen J, Eskelinen EL, Mizushima N, Ohsumi Y, Cattoretti G, Levine B: Promotion of tumorigenesis by heterozygous disruption of the beclin 1 autophagy gene. J Clin Invest 2003, 112:1809-1820.

30. Yue $Z$, Jin S, Yang C, Levine AJ, Heintz N: Beclin 1, an autophagy gene essential for early embryonic development, is a haploinsufficient tumor suppressor. Proc Natl Acad Sci USA 2003, 100:15077-15082.

31. Wu T, Li Y, Gong L, Lu JG, Du XL, Zhang WD, He XL, Wang JQ: Multi-step process of human breast carcinogenesis: a role for BRCA1, BECN1, CCND1, PTEN and UVRAG. Mol Med Report 2012, 5:305-312.

32. Mathew R, Karp CM, Beaudoin B, Vuong N, Chen G, Chen HY, Bray K, Reddy A, Bhanot G, Gelinas C, Dipaola RS, Karantza-Wadsworth V, White E: Autophagy suppresses tumorigenesis through elimination of p62. Cell 2009, 137:1062-1075.

33. Bae H, Guan JL: Suppression of autophagy by FIP200 deletion impairs DNA damage repair and increases cell death upon treatments with anticancer agents. Mol Canc Res 2011, 9:1232-1241.

34. Lu Z, Luo RZ, Lu Y, Zhang X, Yu Q, Khare S, Kondo S, Kondo Y, Yu Y, Mills GB, Liao WS, Bast RC Jr: The tumor suppressor gene ARHI regulates autophagy and tumor dormancy in human ovarian cancer cells. J Clin Invest 2008, 118:3917-3929.

35. Feng W, Marquez RT, Lu Z, Liu J, Lu KH, Issa JP, Fishman DM, Yu Y, Bast RC $\mathrm{Jr}$ : Imprinted tumor suppressor genes ARHI and PEG3 are the most frequently down-regulated in human ovarian cancers by loss of heterozygosity and promoter methylation. Cancer 2008, 112:1489-1502.

36. Fu LL, Wen X, Bao JK, Liu B: MicroRNA-modulated autophagic signaling networks in cancer. Int J Biochem Cell Biol 2012, 44:733-736.

37. Zhu H, Wu H, Liu X, Li B, Chen Y, Ren X, Liu CG, Yang JM: Regulation of autophagy by a beclin 1-targeted microRNA, miR-30a, in cancer cells. Autophagy 2009, 5:816-823. 
38. Korkmaz G, le Sage C, Tekirdag KA, Agami R, Gozuacik D: miR-376b controls starvation and mTOR inhibition-related autophagy by targeting ATG4C and BECN1. Autophagy 2012, 8:165-176.

39. Frankel LB, Wen J, Lees $M$, Høyer-Hansen M, Farkas T, Krogh A, Jäättelä $M$, Lund $A H$ : microRNA-101 is a potent inhibitor of autophagy. EMBO J 2011, 30:4628-4641.

40. Meenhuis A, van Veelen PA, de Looper $H$, van Boxtel N, van den Berge IJ, Sun SM, Taskesen E, Stern P, de Ru AH, van Adrichem AJ, Demmers J, Jongen-Lavrencic M, Löwenberg B, Touw IP, Sharp PA, Erkeland SJ: MiR-17/ 20/93/106 promote hematopoietic cell expansion by targeting sequestosome 1-regulated pathways in mice. Blood 2011, 118:916-925

41. Brest $P$, Lapaquette $P$, Souidi $M$, Lebrigand $K$, Cesaro A, Vouret-Craviari V, Mari B, Barbry P, Mosnier JF, Hébuterne X, Harel-Bellan A, Mograbi B, Darfeuille-Michaud A, Hofman P: A synonymous variant in IRGM alters a binding site for miR-196 and causes deregulation of IRGM-dependent xenophagy in Crohn's disease. Nat Genet 2011, 43:242-245.

42. Chang Y, Yan W, He X, Zhang L, Li C, Huang H, Nace G, Geller DA, Lin J, Tsung A: miR-375 Inhibits Autophagy and Reduces Viability of Hepatocellular Carcinoma Cells Under Hypoxic Conditions. Gastroenterology 2012, 143:177-187. e8.

43. Roccaro AM, Sacco A, Jia X, Azab AK, Maiso P, Ngo HT, Azab F, Runnels J, Quang P, Ghobrial IM: microRNA-dependent modulation of histone acetylation in Waldenstrom macroglobulinemia. Blood 2010, 116:1506-1514.

44. Lee JY, Koga H, Kawaguchi Y, Tang W, Wong E, Gao YS, Pandey UB, Kaushik S, Tresse E, Lu J, Taylor JP, Cuervo AM, Yao TP: HDAC6 controls autophagosome maturation essential for ubiquitin-selective qualitycontrol autophagy. EMBO J 2010, 29:969-980.

45. Xu T, Su H, Ganapathy S, Yuan ZM: Modulation of autophagic activity by extracellular pH. Autophagy 2011, 7:1316-1322.

46. Hu YL, DeLay M, Jahangiri A, Molinaro AM, Rose SD, Carbonell WS, Aghi MK: Hypoxia-induced autophagy promotes tumor cell survival and adaptation to antiangiogenic treatment in glioblastoma. Cancer Res 2012, 72(7):1773-1783.

47. Harris J: Autophagy and cytokines. Cytokine 2011, 56:140-144.

48. Liu XW, Su Y, Zhu H, Cao J, Ding WJ, Zhao YC, He QJ, Yang B: HIF-1adependent autophagy protects HeLa cells from fenretinide (4-HPR)induced apoptosis in hypoxia. Pharmacol Res 2010, 62:416-425.

49. Filomeni G, Desideri E, Cardaci S, Graziani I, Piccirillo S, Rotilio G, Ciriolo MR: Carcinoma cells activate AMP-activated protein kinase-dependent autophagy as survival response to kaempferol-mediated energetic impairment. Autophagy 2010, 6:202-216.

50. Dittmer A, Fuchs A, Oerlecke I, Leyh B, Kaiser S, Martens JW, Lützkendorf J, Müller L, Dittmer J: Mesenchymal stem cells and carcinoma-associated fibroblasts sensitize breast cancer cells in 3D cultures to kinase inhibitors. Int J Oncol 2011, 39:689-696.

51. Castello-Cros R, Bonuccelli G, Molchansky A, Capozza F, Witkiewicz AK, Birbe RC, Howell A, Pestell RG, Whitaker-Menezes D, Sotgia F, Lisanti MP: Matrix remodeling stimulates stromal autophagy, "fueling" cancer cell mitochondrial metabolism and metastasis. Cell Cycle 2011, 10:2021-2034

52. Lazova R, Chakraborty A, Pawelek JM: Leukocyte-cancer cell fusion: initiator of the warburg effect in malignancy? Adv Exp Med Biol 2011 714:151-172.

53. Kurman RJ, Shih IM: The origin and pathogenesis of epithelial ovarian cancer: a proposed unifying theory. Am J Surg Pathol 2010, 34:433-443.

54. Bast RC Jr, Hennessy B, Mills GB: The biology of ovarian cancer: new opportunities for translation. Nat Rev Cancer 2009, 9:415-428.

55. Chen $H$, Hardy TM, Tollefsbol TO: Epigenomics of ovarian cancer and its chemoprevention. Front Genet 2011, 2:67

56. Cancer Genome Atlas Research Network: Integrated genomic analyses of ovarian carcinoma. Nature 2011, 474:609-615.

57. Matulonis UA, Hirsch M, Palescandolo E, Kim E, Liu J, van Hummelen P, MacConaill L, Drapkin R, Hahn WC: High throughput interrogation of somatic mutations in high grade serous cancer of the ovary. PLoS One 2011, 6:e24433.

58. Shen Y, Li DD, Wang LL, Deng R, Zhu XF: Decreased expression of autophagy-related proteins in malignant epithelial ovarian cancer. Autophagy 2008, 4:1067-1068.

59. Tasdemir E, Maiuri MC, Galluzzi L, Vitale I, Djavaheri-Mergny M, D'Amelio M, Criollo A, Morselli E, Zhu C, Harper F, Nannmark U, Samara C, Pinton P, Vicencio JM, Carnuccio R, Moll UM, Madeo F, Paterlini-Brechot P, Rizzuto R,
Szabadkai G, Pierron G, Blomgren K, Tavernarakis N, Codogno P, Cecconi F, Kroemer G: Regulation of autophagy by cytoplasmic p53. Nat Cell Biol 2008, 10:676-687.

60. Lu Z, Luo RZ, Peng H, Rosen DG, Atkinson EN, Warneke C, Huang M, Nishmoto A, Liu J, Liao WS, Yu Y, Bast RC Jr: Transcriptional and posttranscriptional down-regulation of the imprinted tumor suppressor gene ARHI (DRAS3) in ovarian cancer. Clin Cancer Res 2006, 12:2404-2413.

61. Luo RZ, Fang X, Marquez R, Liu SY, Mills GB, Liao WS, Yu Y, Bast RC: ARHI is a Ras-related small G-protein with a novel $\mathrm{N}$-terminal extension that inhibits growth of ovarian and breast cancers. Oncogene 2003, 22:2897-2909

62. Badgwell DB, Lu Z, Le K, Gao F, Yang M, Suh GK, Bao JJ, Das P, Andreeff M, Chen W, Yu Y, Ahmed AA, S-L Liao W, Bast RC Jr: The tumor-suppressor gene ARHI (DIRAS3) suppresses ovarian cancer cell migration through inhibition of the Stat3 and FAK/Rho signaling pathways. Oncogene 2011 31:68-79.

63. Bao JJ, Le XF, Wang RY, Yuan J, Wang L, Atkinson EN, LaPushin R, Andreeff $M$, Fang B, YU Y, Bast RC Jr: Reexpression of the tumor suppressor gene ARHI induces apoptosis in ovarian and breast cancer cells through a caspase-independent calpain-dependent pathway. Cancer Res 2002, 62:7264-7272

64. Bunkholt Elstrand M, Dong HP, Ødegaard E, Holth A, Elloul S, Reich R, Tropé CG, Davidson B: Mammalian target of rapamycin is a biomarker of poor survival in metastatic serous ovarian carcinoma. Hum Pathol 2010, 41:794-804.

65. Nakayama K, Nakayama N, Kurman RJ, Cope L, Pohl G, Samuels Y, Velculescu VE, Wang TL, Shih IM: Sequence mutations and amplification of PIK3CA and AKT2 genes in purified ovarian serous neoplasms. Canc Biol Ther 2006, 5:779-785.

66. Shoji K, Oda K, Nakagawa S, Hosokawa S, Nagae G, Uehara Y, Sone K, Miyamoto Y, Hiraike H, Hiraike-Wada O, Nei T, Kawana K, Kuramoto H, Aburatani $H$, Yano $T$, Taketani $Y$ : The oncogenic mutation in the pleckstrin homology domain of AKT1 in endometrial carcinomas. Br J Cancer 2009, 101:145-148.

67. Kolasa IK, Rembiszewska A, Janiec-Jankowska A, Dansonka-Mieszkowska A, Lewandowska AM, Konopka B, Kupryjańczyk J: PTEN mutation, expression and LOH at its locus in ovarian carcinomas. Relation to TP53, K-RAS and BRCA1 mutations. Gynecol Oncol 2006, 103:692-697.

68. Davidson B, Hadar R, Schlossberg A, Sternlicht T, Slipicevic A, Skrede M, Risberg B, Flørenes VA, Kopolovic J, Reich R: Expression and clinical role of DJ-1, a negative regulator of PTEN, in ovarian carcinoma. Hum Pathol 2008, 39:87-95.

69. Liang XH, Jackson S, Seaman M, Brown K, Kempkes B, Hibshoosh H, Levine $\mathrm{B}$ : Induction of autophagy and inhibition of tumorigenesis by beclin 1 . Nature 1999, 402:672-676.

70. Crighton D, Wilkinson S, O'Prey J, Syed N, Smith P, Harrison PR, Gasco M, Garrone O, Crook T, Ryan KM: DRAM, a p53-induced modulator of autophagy, is critical for apoptosis. Cell 2006, 126:121-134.

71. Yoon JH, Her S, Kim M, Jang IS, Park J: The expression of damageregulated autophagy modulator 2 (DRAM2) contributes to autophagy induction. Mol Biol Rep 2011, 39:1087-1093.

72. Park SM, Kim K, Lee EJ, Kim BK, Lee TJ, Seo T, Jang IS, Lee SH, Kim S, Lee JH, Park J: Reduced expression of DRAM2/TMEM77 in tumor cells interferes with cell death. Biochem Biophys Res Commun 2009, 390:1340-1344.

73. Bartholomeusz C, Rosen D, Wei C, Kazansky A, Yamasaki F, Takahashi T, Itamochi $\mathrm{H}$, Kondo S, Liu J, Ueno NT: PEA-15 induces autophagy in human ovarian cancer cells and is associated with prolonged overall survival. Cancer Res 2008, 68:9302-9310.

74. Kulbe H, Thompson R, Wilson JL, Robinson S, Hagemann T, Fatah R, Gould D, Ayhan A, Balkwill F: The inflammatory cytokine tumor necrosis factoralpha generates an autocrine tumor-promoting network in epithelial ovarian cancer cells. Cancer Res 2007, 67:585-592.

75. Alvero AB, Montagna MK, Craveiro V, Liu L, Mor G: Distinct subpopulations of epithelial ovarian cancer cells can differentially induce macrophages and T regulatory cells toward a pro-tumor phenotype. Am J Reprod Immunol 2012, 67:256-265.

76. Lane D, Matte I, Rancourt C, Piché A: Prognostic significance of IL-6 and IL-8 ascites levels in ovarian cancer patients. BMC Canc 2011, 11:210.

77. Coward J, Kulbe H, Chakravarty P, Leader D, Vassileva V, Leinster DA Thompson R, Schioppa T, Nemeth J, Vermeulen J, Singh N, Avril N, Cummings J, Rexhepaj E, Jirström K, Gallagher WM, Brennan DJ, McNeish IA, 
Balkwill FR: Interleukin- 6 as a therapeutic target in human ovarian cancer. Clin Cancer Res 2011, 17:6083-6096.

78. Chou CH, Wei LH, Kuo ML, Huang YJ, Lai KP, Chen CA, Hsieh CY: Up-regulation of interleukin- 6 in human ovarian cancer cell via a Gi/PI3K-Akt/NF-kappaB pathway by lysophosphatidic acid, an ovarian cancer-activating factor. Carcinogenesis 2005, 26:45-52.

79. Yu S, Murph MM, Lu Y, Liu S, Hall HS, Liu J, Stephens C, Fang X, Mills GB: Lysophosphatidic acid receptors determine tumorigenicity and aggressiveness of ovarian cancer cells. J Natl Canc Inst 2008, 100:1630-1642.

80. Delk NA, Farach-Carson MC: Interleukin-6: A bone marrow stromal cell paracrine signal that induces neuroendocrine differentiation and modulates autophagy in bone metastatic PCa cells. Autophagy 2012, 8:650-663.

81. Chang $\mathrm{CL}$, Liao JJ, Huang WP, Lee H: Lysophosphatidic acid inhibits serum deprivation-induced autophagy in human prostate cancer PC-3 cells. Autophagy 2007, 3:268-270

82. Boren T, Xiong Y, Hakam A, Wenham R, Apte S, Chan G, Kamath SG, Chen DT, Dressman H, Lancaster JM: MicroRNAs and their target messenger RNAs associated with ovarian cancer response to chemotherapy. Gynecol Oncol 2009, 113:249-255.

83. Mezzanzanica D, Bagnoli M, De Cecco L, Valeri B, Canevari S: Role of microRNAs in ovarian cancer pathogenesis and potential clinical implications. Int J Biochem Cell Biol 2010, 42:1262-1272.

84. Vaksman O, Stavnes HT, Kaern J, Trope CG, Davidson B, Reich R: miRNA profiling along tumour progression in ovarian carcinoma. J Cell Mol Med 2011, 15:1593-1602.

85. Marchini S, Cavalieri D, Fruscio R, Calura E, Garavaglia D, Nerini IF, Mangioni C, Cattoretti G, Clivio L, Beltrame L, Katsaros D, Scarampi L, Menato G, Perego P, Chiorino G, Buda A, Romualdi C, D'Incalci M: Association between miR-200c and the survival of patients with stage I epithelial ovarian cancer: a retrospective study of two independent tumour tissue collections. Lancet Oncol 2011, 12:273-285.

86. Semaan A, Qazi AM, Seward S, Chamala S, Bryant CS, Kumar S, Morris R, Steffes CP, Bouwman DL, Munkarah AR, Weaver DW, Gruber SA, Batchu RB: MicroRNA-101 Inhibits Growth of Epithelial Ovarian Cancer by Relieving Chromatin-Mediated Transcriptional Repression of p21(waf1/cip1). Pharm Res 2011, 28:3079-3090.

87. Su D, Deng H, Zhao X, Zhang X, Chen L, Chen X, Li Z, Bai Y, Wang Y, Zhong Q, Yi T, Qian Z, Wei Y: Targeting CD24 for treatment of ovarian cancer by short hairpin RNA. Cytotherapy 2009, 11:642-652.

88. Zhao Z, Liu XF, Wu HC, Zou SB, Wang JY, Ni PH, Chen XH, Fan QS: Rab5a overexpression promoting ovarian cancer cell proliferation may be associated with APPL1-related epidermal growth factor signaling pathway. Canc Sci 2010, 101:1454-1462.

89. Yang H, Kong W, He L, Zhao JJ, O'Donnell JD, Wang J, Wenham RM, Coppola D, Kruk PA, Nicosia SV, Cheng JQ: MicroRNA expression profiling in human ovarian cancer: miR-214 induces cell survival and cisplatin resistance by targeting PTEN. Cancer Res 2008, 68:425-433.

90. Lou Y, Yang X, Wang F, Cui Z, Huang Y: MicroRNA-21 promotes the cell proliferation, invasion and migration abilities in ovarian epithelial carcinomas through inhibiting the expression of PTEN protein. Int J Mol Med 2010, 26:819-827.

91. Yang HJ, Liu WW, Wang Y, Tsang PC, Ngan HY: Differential DNA methylation profiles in gynecological cancers and correlation with clinico-pathological data. BMC Canc 2006, 6:212.

92. Zalckvar E, Berissi H, Mizrachy L, Idelchuk Y, Koren I, Eisenstein M, Sabanay H, Pinkas-Kramarski R, Kimchi A: DAP-kinase-mediated phosphorylation on the $\mathrm{BH} 3$ domain of beclin 1 promotes dissociation of beclin 1 from $\mathrm{Bcl}-$ $\mathrm{XL}$ and induction of autophagy. EMBO Rep 2009, 10:285-292.

93. Steeves MA, Dorsey FC, Cleveland JL: Targeting the autophagy pathway for cancer chemoprevention. Curr Opin Cell Biol 2010, 22:218-225.

94. Chen N, Karantza V: Autophagy as a therapeutic target in cancer. Canc Biol Ther 2011, 11:157-168.

95. Levy JM, Thorburn A: Targeting autophagy during cancer therapy to improve clinical outcomes. Pharmacol Ther 2011, 131:130-141.

96. Degenhardt K, Mathew R, Beaudoin B, Bray K, Anderson D, Chen G, Mukherjee C, Shi Y, Gélinas C, Fan Y, Nelson DA, Jin S, White E: Autophagy promotes tumor cell survival and restricts necrosis, inflammation, and tumorigenesis. Canc Cell 2006, 10:51-64.
97. Rosenfeldt MT, Ryan KM: The multiple roles of autophagy in cancer. Carcinogenesis 2011, 32:955-963.

98. Castino R, Bellio N, Follo C, Murphy D, Isidoro C: Inhibition of PI3k class IIIdependent autophagy prevents apoptosis and necrosis by oxidative stress in dopaminergic neuroblastoma cells. Toxicol Sci 2010, 117:152-162.

99. Bursch W, Ellinger A, Kienzl H, Török L, Pandey S, Sikorska M, Walker R, Hermann RS: Active cell death induced by the anti-estrogens tamoxifen and ICI 164384 in human mammary carcinoma cells (MCF-7) in culture: the role of autophagy. Carcinogenesis 1996, 17:1595-1607.

100. Yap TA, Carden CP, Kaye SB: Beyond chemotherapy: targeted therapies in ovarian cancer. Nat Rev Cancer 2009, 9:167-181.

101. Bazzaro M, Lin Z, Santillan A, Lee MK, Wang MC, Chan KC, Bristow RE, Mazitschek R, Bradner J, Roden RB: Ubiquitin proteasome system stress underlies synergistic killing of ovarian cancer cells by bortezomib and a novel HDAC6 inhibitor. Clin Cancer Res 2008, 14:7340-7347.

doi:10.1186/1757-2215-5-22

Cite this article as: Peracchio et al.: Involvement of autophagy in ovarian cancer: a working hypothesis. Journal of Ovarian Research 2012 5:22.

\section{Submit your next manuscript to BioMed Central and take full advantage of:}

- Convenient online submission

- Thorough peer review

- No space constraints or color figure charges

- Immediate publication on acceptance

- Inclusion in PubMed, CAS, Scopus and Google Scholar

- Research which is freely available for redistribution 